\title{
Prevalence of Malaria at Booking among Antenatal Clients in a Secondary Health Care Facility in Abeokuta, Nigeria
}

Idowu OA*, Sokunbi OA, Babalola AS

Department of Pure and Applied Zoology, Federal University of Agriculture, Abeokuta, Nigeria

Corresponding author: Idowu OA, Department of Pure and Applied Zoology, Federal University of Agriculture, Abeokuta, Nigeria, Tel: +2348033349340; E-mail: tomiwo2@gmail.com

Received date: February19, 2015; Accepted date: April 27, 2015; Published date: May 5, 2015

Copyright: (C) 2015 Idowu OA et al. This is an open-access article distributed under the terms of the Creative Commons Attribution License, which permits unrestricted use, distribution, and reproduction in any medium, provided the original author and source are credited.

\begin{abstract}
This study aims to determine the prevalence of malaria and anaemia among pregnant women attending their first antenatal care booking in Abeokuta. Blood samples were collected from 222 randomly selected pregnant women attending their first antenatal clinic in a secondary health facility in Abeokuta, Ogun State, Nigeria. Blood samples were screened for malaria parasites using thick film and observed under the microscope. Anaemia was investigated among subjects using haematocrit. Questionnaires were administered to obtain demographic and medical information and data collected were analysed using SPSS 16.0. The prevalence of malaria parasitaemia was $113(50.90 \%)$, and $123(55.0 \%)$ were anaemic. The prevalence of anaemia was found to be high $69(61.1 \%)$ among the pregnant women that tested positive to malaria parasite compared with those that tested negative (48.6\%). A high prevalence of malaria parasite infections $(60.0 \%)$ was recorded among the teenagers (16-19years) compared to that of their older counterparts; $20-30$ years $65(47.8 \%)$ and above 30years $36(54.5 \%)$. A high proportion of the multigravidae $(55.9 \%)$ were positive for malaria parasite, followed secundigravidae $(50.7 \%)$, while the primigravidae recorded the lowest 44(47.8\%) prevalence of malaria infections. Pregnant women that booked for ANC within their first trimester recorded a relatively low prevalence of malaria parasite infections $20(48.8 \%)$ compared to those within their second $90(50.8 \%)$ and third trimester $3(75.0 \%)$ respectively. many pregnant women who start visiting ANC are already malaria positive and anaemic. While IPTp is not recommended until after quickening, an earlier start of LLIN usage, iron and folate supplementation, even before booking, may be beneficial. As the first step, health education strategies should emphasize early clinic attendance.
\end{abstract}

Keywords: Malaria; Antenatal; Booking; Gravidity; Anaemia

\section{Introduction}

Malaria, a parasitic disease caused by Plasmodium species and transmitted by female anopheles mosquitoes remains one of the world most devastating parasitic infections [1]. Malaria remains the most severe and complex health challenge facing the vast majority of the countries in the sub-Saharan Africa [2].

In Nigeria, like other endemic areas, its severe and complicated effects are most common among infants and pregnant women [3]. Four genus of malaria are known to affect human which includes; $P$. vivax, $P$. malariae, $P$. ovale and $P$. falciparum being the most common and virulent [1].

In areas of Stable Malaria transmission, P.falciparum infection in pregnant women is associated with maternal anaemia and Low Birth Weight (LBW) [4-6]. The occurrence of Low Birth Weight had been attributed to intrauterine growth retardation (IUGR) which might have been as a result of placental parasitisation [2] in which the frequency is usually higher among the primigravidae and immuno compromised (HIV) infected mothers [6].

Anaemia in pregnancy continues to be a common problem in many developing countries where poverty, ignorance and disease are still prevalent among the people. Studies have shown that up to $60 \%$ of pregnant women in developing countries including Nigeria may be anaemic, and nearly $7 \%$ of pregnant women are severely anaemic [7-8]. The reported principal causes of anaemia in sub-Saharan Africa include nutritional deficiencies, malaria, other parasitic infestations and infection with human immunodeficiency virus [9]. Malaria can lead to anaemia through parasitic destruction of red blood cells (RBCs) as well as auto immune reaction in which non-infected RBCs are also destroyed.

Early entry into antenatal care is one of the key strategies for reducing maternal and neonatal morbidity and mortality [10]. Studies have shown that the susceptibility to malaria increases early in pregnancy and parasitemia peak at 9-16 weeks [11-13]. Therefore, booking during the first trimester can promote early entry of the pregnant women into adequate care, thereby reducing their rate of exposure to malaria infection [10]. On the other hand, late booking may increase their exposure to malaria infection during pregnancy. Therefore, this study aims to determine the prevalence of malaria and anaemia among pregnant women attending their first antenatal care booking in Abeokuta.

\section{Materials and Methods}

\section{Study site}

The study was conducted at the Oba Ademola II Maternity Hospital, a secondary health facility in Abeokuta south, Ogun state Nigeria. 
Citation: Idowu OA, Sokunbi OA, Babalola AS (2015) Prevalence of Malaria at Booking among Antenatal Clients in a Secondary Health Care

Page 2 of 5

\section{Participants}

The study population consisted of first ANC attendees who were selected for participating on using a random sampling technique to access the prevalence of malaria and anaemia in pregnancy.

\section{Ethical clearance}

The study was approved by the Medical Director of the health facility. Cooperation and ossilauce of other health official of the hospital, and consent of the subjects (pregnant women) was also soughted. Only pregnant women who gave their consent were enrolled for the study.

\section{Study procedures}

Pregnant women attending their first ANC visit were approached to participate in the study. After informed consent was obtained, demographic information as well as information on environmental conditions was obtained from the participants with the aid of a structured questionnaire.

\section{Laboratory methods}

Blood was obtained by venipuncture; blood films were stained in $10 \%$ Giemsa for $15 \mathrm{~min}$ and examined under oil immersion for malaria parasites. A thick film was considered as negative when 100 microscopic fields shows no parasites. Blood samples were considered positive when the asexual blood stage of malaria parasite is present in the peripheral blood. For quality control, $10 \%$ of the negative samples and $20 \%$ of the positive samples were re-examined by different microscopists during the study. The PCV level of pregnant women was measured to the nearest percentage using Haematocrit. Pregnant women with PCV level between 30-33\% were considered to be mildly anaemic, while those with PCV level between $21-30 \%$ and $<21 \%$ were considered to be moderately and severely anaemic respectively.

\section{Data management and statistical analysis}

Responses to the questionnaires administered and the blood sample data form were collated and analysed in accordance to the study objectives, using the statistical package for social science (SPSS) version 16.0 for windows.

\section{Results}

\section{Characteristics of the study population}

A large percentage 136(61.3\%) of the subject examined were between the age group of 21-30 years, followed by age above 30 years $66(29.7 \%)$, while the least proportion of the respondents were teenagers $20(9.0 \%)$. The respondents were mainly traders by profession $106(47.70 \%)$, followed by artisans $50(22.5 \%), 16(7.2 \%)$ of the respondents were student while $18(8.1 \%)$ and $14(6.3 \%)$ of the respondents were civil servants and unemployed respectively (Table 1). Furthermore, $99(44.60 \%)$ of the respondent had secondary education, while $78(35.1 \%)$ and $40(18.0 \%)$ of the respondents had tertiary and primary education respectively (Table 1).

A high proportion of the primigravidae registered for antenatal during the first trimester compared to other gravidaes. However, most of the pregnant women including the primigravidae registered during second trimester (Figure 1).

\begin{tabular}{|c|c|c|}
\hline Variables & Frequency (N) & Percentage N (\%) \\
\hline \multicolumn{3}{|l|}{ Age (Years) } \\
\hline Teenagers & 20 & 9 \\
\hline $21-30$ years & 136 & 61.3 \\
\hline Above 30 years & 66 & 29.7 \\
\hline Total & 222 & 100 \\
\hline \multicolumn{3}{|l|}{ Occupation } \\
\hline Teaching & 17 & 7.7 \\
\hline civil servant & 18 & 8.1 \\
\hline Trader & 106 & 47.7 \\
\hline Student & 16 & 7.2 \\
\hline Unemployed & 14 & 6.3 \\
\hline Artisans & 50 & 22.5 \\
\hline Banker & 1 & 0.5 \\
\hline \multicolumn{3}{|l|}{ Educational status } \\
\hline No formal Education & 5 & 2.3 \\
\hline Primary & 40 & 18 \\
\hline Secondary & 99 & 44.6 \\
\hline Tertiary & 78 & 35.1 \\
\hline
\end{tabular}

Table 1: Characteristics of the respondents

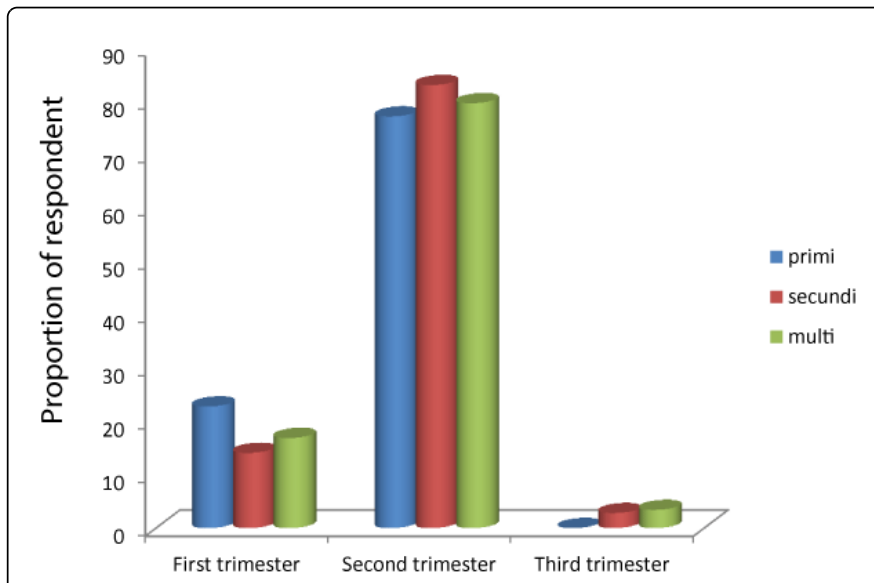

Figure 1: Gestational age at first antenatal booking among pregnant women with different gravid status

\section{Prevalence of malaria and anaemia among the respondents}

The prevalence of Malaria was 113(50.9\%) while the prevalence of anaemia among the pregnant women was $122(55.0 \%)$ (Table 2). The prevalence of anaemia was found to be high 69(61.1\%) among the pregnant women that tested positive to malaria parasite compared 
Citation: Idowu OA, Sokunbi OA, Babalola AS (2015) Prevalence of Malaria at Booking among Antenatal Clients in a Secondary Health Care Facility in Abeokuta, Nigeria. Clinics Mother Child Health 12: 177. doi:10.4172/2090-7214.1000177

Page 3 of 5

with those that tested negative (48.6) (Table 2). However, this observation does not reach a statistically significant level $(\mathrm{p}>0.05)$.

\begin{tabular}{|c|c|c|c|}
\hline Malaria Status & Anaemia Status & \\
\hline & $\begin{array}{c}\text { No. Examined (N } \\
\%)\end{array}$ & Anaemic (N\%) & Non Anaemic (N\%) \\
\hline Positive & $113(50.9)^{\star *}$ & $69(61.1)^{\star}$ & $44(38.9)^{*}$ \\
\hline Negative & $109(49.1)^{\star *}$ & $53(48.6)^{\star}$ & $56(51.4)^{*}$ \\
\hline Total & $222(100.0)$ & $122(55.0)^{*}$ & $99(45.0)^{*}$ \\
\hline
\end{tabular}

Note: "percentage within group (in a row), ${ }^{* *}$ percentage of the total (in a column).

Table 2: Prevalence of malaria and anaemia among the pregnant women

\section{Prevalence of malaria parasite infections by age, gravidity} and gestational age at booking among the pregnant women

A high prevalence of malaria parasite infections (60.0\%) was recorded among the teenagers (16-19years) compared to that of their older counterparts; $20-30$ years $65(47.8 \%)$ and above 30 years $36(54.5 \%)$ (Table 3). However, this observation was not statistically significant $(\mathrm{p}>0.05)$.There was no significant relationship between gravidity and prevalence of malaria parasites infections among the pregnant women as a high proportion of the multigravidae $(55.9 \%)$ were positive for malaria parasite, this was followed secundigravidae (50.7\%), while the primigravidae recorded the lowest $44(47.8 \%)$ prevalence of malaria parasite infections (Table 3).

Pregnant women that booked for ANC within their first trimester recorded a relatively low prevalence of malaria parasite infections 20(48.8\%) compared to those within their second 90(50.8\%) and third trimester $3(75.0 \%)$ respectively (Table 1 ).

\begin{tabular}{|c|c|c|c|}
\hline \multirow{2}{*}{ Variables } & Examined & \multicolumn{2}{|c|}{ Malaria Status } \\
\cline { 2 - 4 } & $\mathbf{N}(\%)$ & Positive & Negative \\
\cline { 2 - 4 } & & N (\%) & N (\%) \\
\hline Age & $222(100.0)$ & & p-value=0.061 \\
\hline Teenagers (16-19 years) & $20(9.0)$ & $12(60.0)$ & $8(40.0)$ \\
\hline 20-30 years & $136(61.3)$ & $65(47.8)$ & $71(52.2)$ \\
\hline Above 30 years & $66(29.7)$ & $36(54.5)$ & $30(45.5)$ \\
\hline Gravidity & $222(100.0)$ & & p-value=0.480 \\
\hline Primigravidae & $92(41.4)$ & $44(47.8)$ & $48(52.2)$ \\
\hline Secundigravidae & $71(31.9)$ & $36(50.7)$ & $3549.3)$ \\
\hline Multigravidae & $59(26.7)$ & $33(55.9)$ & $26(44.1)$ \\
\hline Gestational age at booking & $222(100.0)$ & & p-value=0.332 \\
\hline 1st trimester & $41(18.5)$ & $20(48.8)$ & $21(51.2)$ \\
\hline Second trimester & $177(79.7)$ & $90(50.8)$ & $87(49.2)$ \\
\hline
\end{tabular}

\begin{tabular}{|l|l|l|l|}
\hline Third Trimester & $4(1.8)$ & $3(75.0)$ & $1(25.0)$ \\
\hline
\end{tabular}

Table 3: Prevalence of malaria parasite infections by age, gravidity and gestational age among the pregnant women at booking

\section{Impact of environmental factors on prevalence of malaria parasites among the pregnant women}

There was no significant relationship $(\mathrm{p}>0.05)$ between environmental conditionsand prevalence of malaria parasite infections among the pregnant women. A high proportion of the pregnant women who claimed that there was presence of stagnant water $(53.3 \%)$ and bushes $(48.4 \%)$ around their homes tested positive to malaria parasite compared with those who did not notice the presence of stagnant water $(50.3 \%)$ and bushes $(54.2 \%)$ around their homes (Table $4)$.

\begin{tabular}{|c|c|c|c|}
\hline Variables & $\begin{array}{c}\text { Number Examined N } \\
\%\end{array}$ & \multicolumn{2}{|l|}{ Malaria Status } \\
\hline & & $\begin{array}{c}\text { Positive N } \\
(\%)\end{array}$ & Negative N (\%) \\
\hline $\begin{array}{c}\text { Presence of } \\
\text { stagnant water }\end{array}$ & $222(100.0)$ & & p-value =0.613 \\
\hline Yes & $43(19.4)$ & $23(53.5)$ & $20(46.5)$ \\
\hline No & $179(80.6)$ & $90(50.3)$ & $89(49.7)$ \\
\hline Presence of Bushes & $222(100.0)$ & & p-value=0.432 \\
\hline Yes & $126(56.8)$ & $61(48.4)$ & $65(51.6)$ \\
\hline No & $96(43.2)$ & $52(54.2)$ & $44(45.8)$ \\
\hline
\end{tabular}

Table 4: Impact of environmental factors on prevalence of malaria parasite infections among the pregnant women at booking

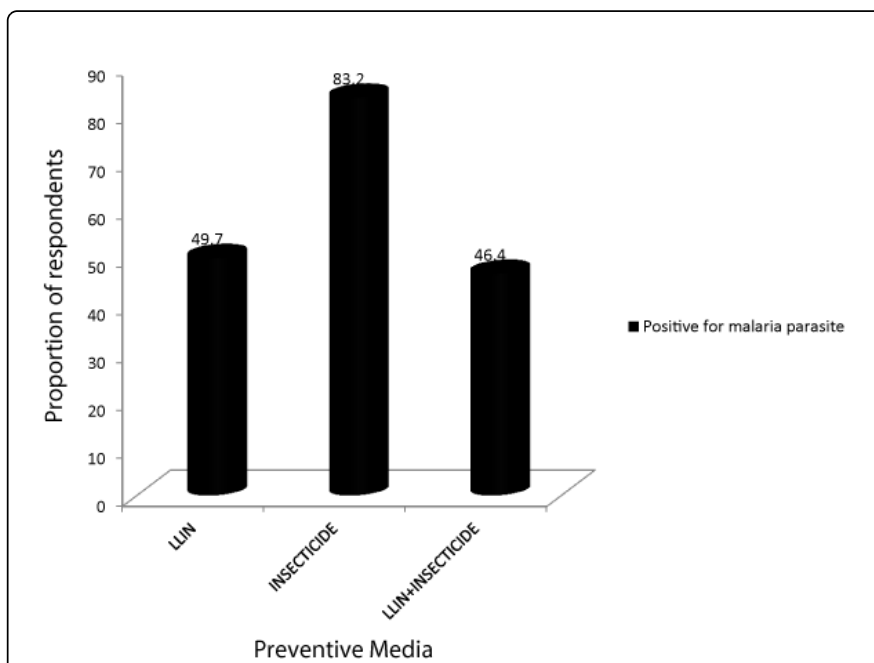

Figure 2: Effect of preventive measures on prevalence of malaria infections among pregnant women at first antenatal booking. 


\section{Effect of preventive measures on the prevalence of malaria parasites among the pregnant women}

The prevalence of malaria parasite infections was slightly lower (49.7\%) among the pregnant women that sleeps under the Long Lasting Insecticidal Nets (LLINs) compared with those that did not $(50.3 \%)$. However, the difference is not significant ( $p>0.05)$. The use of insecticides seems not to be effective in preventing the transmission of malaria parasites as $83.2 \%$ of the pregnant women who claimed to use insecticides alone as a preventive tool against malaria parasite infections tested positive for malaria parasite. However, the combination of both LLIN and Insecticides seems to be the most effective as the lowest prevalence $(46.4 \%)$ of malaria parasite infections was recorded among those who combined both LLINs and insecticides (Figure 2).

\section{Discussion}

Screening for Malaria and anaemia during booking among pregnant women is imperative, as it afford them the opportunity to prevent complications associated with these diseases. The prevalence of malaria and anaemia at first antenatal booking in this study was $50.9 \%$ and $55.0 \%$ respectively. Data from the literature in developing countries have reported prevalence of anaemia in pregnancy that ranged from 35.0 to $75.0 \%$ [14]. The prevalence of anaemia reported in this study is consistent with some other findings in different part of Nigeria $[9,15-16]$.

The high prevalence of anaemia in this study may be attributed to the low socioeconomic status of the women, which may have impact on their nutritional status and health seeking behavior $[9,17]$. The prevalence of anaemia in this study is in agreement to the deductions made by Olujimi et al., [16] that even after 25 years of WHO estimate that the prevalence of anaemia among pregnant women in Africa is $56.0 \%$ [18], the situation has only marginally improved.

The high prevalence of malaria parasite infections among the teenagers recorded in this study could be attributable to their lateness in antenatal booking as well as low level of immunity against the malaria parasites. Most of these teenagers registered towards the end of the second trimester, thereby increasing their susceptibility to malaria parasite even before they booked.

The observed pattern of late booking during the second and third trimester for antenatal care recorded in this study is in keeping with previous reports [19-20].

The low prevalence of malaria infections recorded among the pregnant women that booked earlier (1st trimester), compared with those that registered later could be attributable to health seeking behaviors and practices towards the prevention of malaria parasites including the prior use of LLIN and anti-malaria drug before booking [9].

Though not statistically significant, the presence of bushes and stagnant water around the houses of the participants were associated with high prevalence of malaria parasite infections. Bushes and stagnant water serves as breeding sites for mosquito vectors [21-22] that transmits the malaria parasites, thereby increasing the prevalence of malaria infections in such area where they exist.

The usage of LLIN barely reduces the prevalence of malaria infections among the pregnant women. This could be attributable to the pattern of usage. Though claiming that they use LLIN, most of these pregnant women do not sleep regularly under the net, which in turn is as good not having the net.

A very high prevalence of malaria infections was detected among those that relied solely on insecticides in preventing malaria infections. Studies had reported resistance of female Anopheles mosquitoes to various forms of insecticides [23].

Combination of LLIN and Insecticides showed the best efficacy against malaria infections in this study. This is an indication that the best preventive measure against malaria infections during pregnancy should always involve an integrated approach.

\section{Conclusion}

This study had shown that many pregnant women who start visiting ANC are already positive to malaria parasite and anaemic. While IPTp is not recommended until after quickening, an earlier start of LLIN usage, iron and folate supplementation, even before booking, may be beneficial. As the first step, health education strategies should emphasize early clinic attendance as recommended by the WHO [5].

\section{References}

1. National center for infectious disease, division of parasitic disease (NCID) (2004) Anopheles mosquitoes.

2. Uneke CJ (2009) Impact of home management of Plasmodium falciparum malaria on childhood malaria control in sub-Saharan Africa. Trop Biomed 26: 182-199.

3. Warrell DA (1997) Cerebral malaria: Clinical features, pathophysiology and treatment. Ann Trop Med Parasitology 91: 875-884.

4. Steketee RW, Nahlen BL, Parise ME, Menendez C (2001) The burden of malaria in pregnancy in malaria-endemic areas. Am J Trop Med Hyg 64: 28-35.

5. WHO/AFRO (2004) A strategic Framework For Malaria Prevention and Control During Pregnancy in the African region.

6. Desai M, ter Kuile FO, Nosten F, McGready R., Asamoa, et al. (2007) Epidemiology and burden of malaria in pregnancy. Lancet Infect Dis 7: 93-104.

7. World Health Organization (1992) The Prevalence of Anaemia in Women: A tabulation of available information (2nd edn.) WHO, Geneva.

8. Akinyinka OO (2004) Recent trends in the management of anaemia in pregnancy. Trop J Obstet Gynaecol 21: 1-3.

9. Anorlu RI, Oluwole AA, Abudu OO (2006) Sociodemographic factors in anaemia in pregnancy at booking in Lagos, Nigeria. J Obstet Gynaecol 26: 773-776.

10. W.H.O. (2012) WHO Policy Brief for the Implementation of Intermittent Preventive Treatment of Malaria in Pregnancy using SulfadoxinePyrimethamine (IPTp-SP). WHO, Geneva, Switzerland, pp.1-10.

11. Brabin BJ (1983) An analysis of malaria in pregnancy in Africa. Bull World Health Organ 61: 1005-1016.

12. Brabin BJ (1991) The Risks of Severity of Malaria in Pregnant Women. Applied field Research in malaria; Report No 1. World health Organization, Geneva.

13. Jauniaux E, Gulbis B, Burton GJ (2003) The human first trimester gestational sac limits rather than facilitates oxygen transfer to the foetus -a review. Placenta 24: 86-93.

14. Omigbodun AO (2004). Recent trends in the management of anaemia in pregnancy. Trop J Obstet Gynaecol 21: 1-3.

15. Agan TU, Ekabua JE, Udoh AE, Ekanem EI, Efiok EE, et al. (2010) Prevalence of anemia in women with asymptomatic malaria parasitemia at first antenatal care visit at the University of Calabar Teaching Hospital, Calabar, Nigeria. Int J Womens Health 2: 229-233.

16. Olujimi AO, Aniekan MA, Emem AB, Robert SJ, Godwin I, Anyiekere M (2014) BioMed Res Intern 2014: 8. 
Citation: Idowu OA, Sokunbi OA, Babalola AS (2015) Prevalence of Malaria at Booking among Antenatal Clients in a Secondary Health Care Facility in Abeokuta, Nigeria. Clinics Mother Child Health 12: 177. doi:10.4172/2090-7214.1000177

Page 5 of 5

17. Komolafe JO, Kuti O, Oni O, Egbewale BE (2005) Sociodemographic characteristics of anaemic gravidae at booking: a preliminary study at Ilesha,Western Nigeria. Nigerian Med J 14: 151-154.

18. Sarr D, Marrama L, Gaye A, Dangou JM, Niang M, et al (2006) High prevalence of placental malaria and low birth weight in Sahelian periurban area. Am J Trop Med Hyg 75: 171-177.

19. Okunlola MA, Ayinde OA, Owonikoko KM, Omigbodun AO (2006) Factors influencing gestational age at antenatal booking at the University College Hospital, Ibadan, Nigeria. J Obstet Gynaecol 26: 195 -197.
20. Mafiana CF (1989) Observation of mosquito species breeding in open drains and test containers in Lagos Nigeria. Bioscien Res Communi 1: 95-102.

21. Aigbodion FI, Anyiwe MA (2005). Mosquitoes and the environment: some economic costs of Malaria in Nigeria. Nigeria J Entom 22: 93-107.

22. WHO (2012) Evidence Review Group: Intermittent Preventive Treatment of malaria in pregnancy (IPTp) with SulfadoxinePyrimethamine (SP). WHO Headquarters, Geneva . 